\title{
Intact Four-atom Organic Tetracation Stabilized by Charge Localization in the Gas Phase
}

Tomoyuki Yatsuhashi, Kazuo Toyota, Naoya Mitsubayashi, Masatoshi Kozaki, Keiji Okada, Nobuaki Nakashima

\begin{tabular}{|c|l|}
\hline Citation & ChemPhysChem. 17(19); 2977-2981 \\
\hline Issue Date & $2016-10-05$ \\
\hline Type & Journal Article \\
\hline Textversion & author \\
\hline $\begin{array}{c}\text { Supporting } \\
\text { Information }\end{array}$ & Supporting Information is available at https://doi.org/10.1002/cphc.201600555 \\
\hline & $\begin{array}{l}\text { This is the peer reviewed version of the following article: YATSUHASHI T, TOYOTA } \\
\text { K, MITSUBAYASHI N, KOZAKI M, OKADA K, \& NAKASHIMA N. (2016). Intact } \\
\text { Four-atom Organic Tetracation Stabilized by Charge Localization in the Gas Phase. } \\
\text { Chemphyschem: a European Journal of Chemical Physics and Physical Chemistry. } \\
17,2977-2981 ., \text { which has been published in final form at } \\
\text { http://doi.org/10.1002/cphc.201600555 } \\
\text { This article may be used for non-commercial purposes in accordance with Wiley } \\
\text { Terms and Conditions for Self-Archiving. }\end{array}$ \\
\hline DOI & \begin{tabular}{l} 
10.1002/cphc.201600555 \\
\hline
\end{tabular} \\
\hline
\end{tabular}

\author{
Self-Archiving by Author(s) \\ Placed on: Osaka City University
}

YATSUHASHI T, TOYOTA K, MITSUBAYASHI N, KOZAKI M, OKADA K, \& NAKASHIMA N. (2016). Intact Four-atom Organic Tetracation Stabilized by Charge Localization in the Gas Phase. ChemPhysChem: a European Journal of Chemical Physics and Physical Chemistry. 17, 2977-2981. https://doi.org/10.1002/cphc.201600555 


\title{
Intact Four-atom Organic Tetracation Stabilized by Charge Localization in the Gas Phase
}

\author{
Tomoyuki Yatsuhashi, ${ }^{[a]}[\mathrm{bb}]$ Kazuo Toyota, ${ }^{[a]}$ Naoya Mitsubayashi, ${ }^{[a]}$ Masatoshi Kozaki, ${ }^{[a]}$ Keiji Okada, ${ }^{[a]}$ \\ and Nobuaki Nakashima ${ }^{[a]}$
}

\begin{abstract}
Several features distinguish intact multiply charged molecular cations (MMCs) from other species such as monocations and polycations: high potential energy, high electron affinity, a high density of electronic states with various spin multiplicities, and charge-dependent reactions. However, repulsive Coulombic interactions make MMCs quite unstable, and hence small organic MMCs are currently not readily available. Herein, we report that the isolated four-atom molecule diiodoacetylene survives after the removal of four electrons via tunneling. We show that the tetracation remains metastable towards dissociation because of the localization $(91-95 \%)$ of the positive charges on the terminal iodine atoms, ensuring minimum Coulomb repulsion between adjacent atoms as well as maximum charge-induced attractive dipole interactions between iodine and carbon. Our approach making use of iodines as the positively charged sites enables small organic MMCs to be intact.
\end{abstract}

Successive removal of electrons from molecules by means of tunneling in strong laser fields opens the way to generate multiply charged atoms ${ }^{[1]}$ as well as multiply charged molecular cations (MMCs) in abundance. ${ }^{[2]}$ During the past decades, the prompt dissociation of MMCs into atomic ions, namely Coulomb explosion, has attracted attentions. For example, Coulomb explosion was utilized for clarifying fragmentation processes ${ }^{[3]}$ as well as molecular structure imaging. ${ }^{[4]}$ On the contrary, intact MMCs have been little explored to date although they have the potential to be a reactive species ${ }^{[5]}$ due to their high electron affinity as well as high potential energy, and to provide an opportunity to understand how electron-deficient molecules maintain their chemical bonding. ${ }^{[6-8]}$ In addition, high density of electronic states with various spin multiplicities, and chargedependent reactions, that makes them interesting from both fundamental and applied scientific perspectives. However, confinement of multiple positive charges in a small organic molecule is, in the usual manner, unexpected. Thus, a simple question arises: How many electrons can be removed from an isolated molecule without fragmentation? Diatomic trications ${ }^{[9,10]}$ and a tetracation ${ }^{[11]}$ have been reported for inorganic molecules. On the other hand, the smallest organic trications ever detected

[a] Prof. Dr. T. Yatsuhashi, Dr. K. Toyota, Mr. N. Mitsubayashi, Prof. Dr. M. Kozaki, Prof. Dr. K. Okada, Prof. Dr. N. Nakashima Graduate School of Science

Osaka City University

3-3-138 Sugimoto, Sumiyoshi, Osaka 558-8585 (Japan)

E-mail: tomo@sci.osaka-cu.ac.jp

Homepage: http://www.laserchem.jp

[b] Prof. Dr. T. Yatsuhahshi

PRESTO, Japan Science and Technology Agency

4-1-8 Honcho Kawaguchi, Saitama 332-0012 (Japan)

Supporting information for this article is given via a link at the end of the document. were those of furan and thiophene ( 9 atoms each. $)^{[12]}$ Meanwhile, the production of organic tetracations has been accomplished using several methods, ${ }^{[13-15]}$ but only for large aromatic hydrocarbons, and intact charge states greater than 5 have been reported only for fullerene. ${ }^{[16]}$ The reduction of Coulomb repulsion by the delocalization of positive charges over the molecule enables large aromatic tetracations to maintain their chemical bondings. Indeed, anthracene (24 atoms) is the smallest organic tetracation ever reported. ${ }^{[17]}$ Thus, the second question and challenge arises: How small is the smallest organic molecule that can survive after the removal of three or four electrons?

Here, we report the efficient production of tri- and tetracations of diiodoacetylene $\left(\mathrm{C}_{2} \mathrm{I}_{2}, \mathrm{DIA}\right)$ and diiododiacetylene $\left(\mathrm{C}_{4} \mathrm{I}_{2}, \mathrm{DIDA}\right)$ via tunneling. Needless to say, prompt Coulomb explosion takes place even in the cases of DIA and DIDA when destructive Coulomb forces dominate. The heavy mass effects on the prompt Coulomb explosion of DIA and DIDA was investigated under such conditions. ${ }^{[18]}$ Although the number of charge is smaller, the appearance of the tetracation of such a small $\pi$-moiety is still surprising, and cannot be explained as in the case of large aromatic hydrocarbons. According to our density functional theory (DFT) calculations, the stability of the surprisingly small DIA tetracation is explained in terms of the dominant (91-95\%) localization of the positive charges on the terminal iodine atoms; in such a condition, Coulombic repulsions between iodine and carbon atoms (and between carbon atoms) in the DIA tetracation are minimized.

Intact tri- and tetracations of DIA and DIDA were generated in abundance (Figures 1a, 1b, S1 and S2) in femtosecond laser fields $\left(0.8 \mu \mathrm{m}, 45 \mathrm{fs},>10^{14} \mathrm{Wcm}^{-2}\right)$. Some atomic ions such as iodines and carbons were observed but they were not originated from MMCs $(\leq 4+)$ but from more highly charged states ${ }^{[18]}$ judging from their kinetic energy estimated by the peak splitting. MMCs were definitively identified by the mass-to-charge ratio $(\mathrm{m} / \mathrm{z})$, isotope pattern, and narrower peak width than those of lower-charged ions. For example, a single peak appeared at $\mathrm{m} / \mathrm{z}$ $=69.5$ was not $\mathrm{Cl}^{2+}$ but $\mathrm{DIA}^{4+}\left({ }^{12} \mathrm{C}_{2} \mathrm{l}_{2}{ }^{4+}\right) . \mathrm{Cl}^{2+}$, a doubly charged ion of a symmetrically split DIA, should be produced by the Coulomb explosion. Therefore, $\mathrm{Cl}^{2+}$, if it exists, appears as a double peak owing to its certain kinetic energy. ${ }^{[18]}$ Furthermore, a single peak appeared at $m / z=69.75$ (Figure S2) was assigned to the isotope peak of $\mathrm{DIA}^{4+}\left({ }^{12} \mathrm{C}^{13} \mathrm{Cl}_{2}{ }^{4+}\right)$ based on its position as well as intensity relative to that of dominant peak $\left({ }^{12} \mathrm{C}_{2} \mathrm{I}_{2}{ }^{4+}\right)$. The resolutions of the peaks $\left(m / \Delta m\right.$, fwhm) were $930\left(D^{2} A^{+}\right)$, $1.15 \times 10^{3}\left(\mathrm{DIA}^{2+}\right), 1.37 \times 10^{3}\left(\mathrm{DIA}^{3+}\right)$, and $1.58 \times 10^{3}\left(\mathrm{DIA}^{4+}\right) . \mathrm{A}$ single peak appeared at $m / z=75.5$ was also definitively identified not as $\left.\mathrm{C}_{2}\right|^{2+}$ but as $\operatorname{DIDA}^{4+}\left({ }^{12} \mathrm{C}_{4} \mathrm{l}_{2}{ }^{4+}\right)$ by isotopic analysis. 

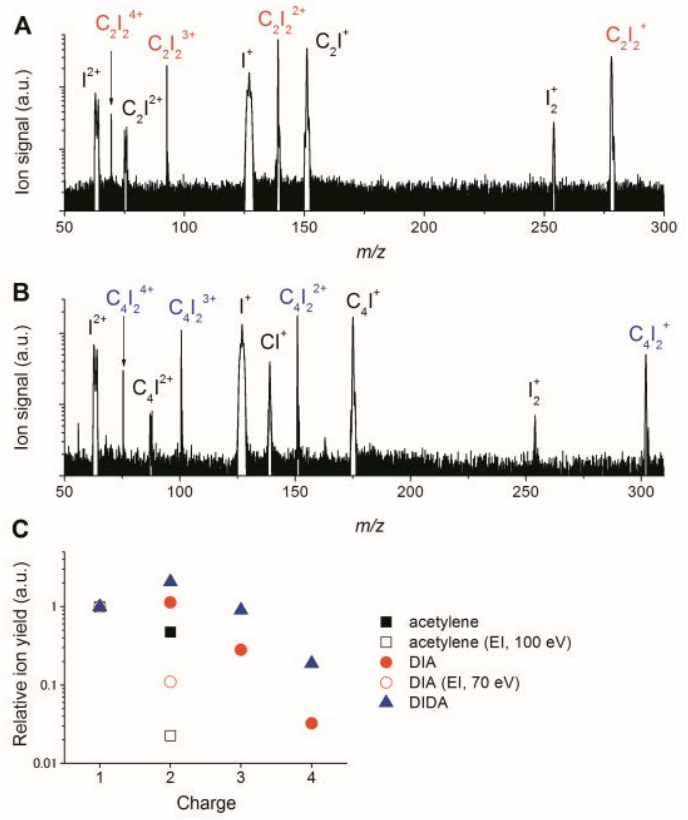

Figure 1. Mass spectra of $A$ ) diiodoacetylene at $3.6 \times 10^{14} \mathrm{Wcm}^{-2}$, and $B$ ) diiododiacetylene at $4.0 \times 10^{14} \mathrm{Wcm}^{-2}$, respectively. Laser polarization was orthogonal to the ion flight axis. C) Relative yields of multiply charged molecular cations with respect to the corresponding monocations. Electron ionization (EI) data were taken from Refs. 19 and 20. fact that acetylene MMCs $(\geq 3+)$ are promptly dissociated into atomic ions ${ }^{[22]}$ because of bond elongation in intense laser fields. [23] Contrary to acetylene, however, some fragment ions (DIA, $\mathrm{C}_{2}{ }^{+}, \mathrm{C}_{2} \mathrm{I}^{+}$, and $\mathrm{C}_{2} \mathrm{I}^{2+}$; DIDA $, \mathrm{C}_{2}{ }^{+}, \mathrm{C}_{3}{ }^{+}, \mathrm{C}_{4}{ }^{+}, \mathrm{C}_{4} \mathrm{I}^{+}, \mathrm{C}_{4} \mathrm{I}^{2+}$, and $\mathrm{Cl}^{+}$) were clearly observed in the mass spectra of diiodoacetylene derivatives. We conclude that the persistence of terminal iodine atoms in close proximity to carbon framework, even in the MMCs of DIA and DIDA, results in the formation of these fragment ions. ${ }^{[18]}$

The persistence of chemical bond for electron removal depends on the character of molecular orbitals where electrons are ejected. The first electron was considered to be removed from the HOMO because the angular distribution of the electron stripped from small molecules via tunneling was strongly correlated with the shape of the highest occupied molecular orbital (HOMO) ${ }^{[24]}$ Figure 2 shows the molecular orbitals (MOs) of the three acetylene derivatives in the neutral ground state. We found that those MOs differed in their positions and numbers of nodes, are important to clarify the stability of MMCs. When an electron is removed from a degenerate $\mathrm{HOMO}$, the $\mathrm{C}-\mathrm{H}$, and $\mathrm{C}-$ $\mathrm{C}$ bonds would be weakened because of their bonding characteristics, whereas the $\mathrm{C}-\mathrm{I}$ bond would be strengthened because of its antibonding characteristic. These expectations were confirmed by the results of the vibrational frequency analysis of the corresponding stretching modes of the acetylene $^{[25]}$ and DIA monocations. ${ }^{[26]}$
On the contrary, the maximum charge state for acetylene was 2 (Figure S1). Thus, substitution of hydrogen atoms for iodine enables acetylene to accept twice the positive charge without fragmentation, even though the number of atoms is the same. Electron ionization data indicated that neither the acetylene $^{[19]}$ nor DIA trication ${ }^{[20]}$ were formed, and the relative abundance of dications was one order of magnitude less than those obtained in femtosecond laser fields (Figure 1c). Furthermore, it is interesting to note that DIDA yielded a greater amount tetracation than DIA, indicating that flexible structure of DIDA with a central $\mathrm{C}-\mathrm{C}$ single bond did not have a destructive influence on the stability of DIDA MMCs.

The detection of MMCs indicated that they were sufficiently stable to leave the ion source intact; thus, the lifetimes of MMCs were longer than their acceleration times $(>0.84 \mu$ s for the DIA tetracation, $>0.88 \mu \mathrm{s}$ for the DIDA tetracation, and $>0.36 \mu \mathrm{s}$ for the acetylene dication) in the mass spectrometer. Furthermore, we detected DIA tetracation by using an offset quadratic-field reflectron, which can distinguish post source decay in the drift region in the mass spectrometer. Thus, DIA tetracation does not decay completely at least for $11 \mu \mathrm{s}$, which is the flight time of DIA tetracation from the ion source to the entrance of the reflectron.

The fragment ion distributions indicate that the $\mathrm{C}-\mathrm{I}$ bond is more resistant than $\mathrm{C}-\mathrm{H}$ bond for electron removals. The mass spectrum of acetylene was composed of atomic and molecular ions with little amount of fragment ions such as $\mathrm{C}_{2} \mathrm{H}^{+}(<1 \%$ with respect to $\mathrm{C}_{2} \mathrm{H}_{2}{ }^{+}$), as previously reported by Cornaggia et al. [21] The absence of fragment ions for acetylene is explained by the

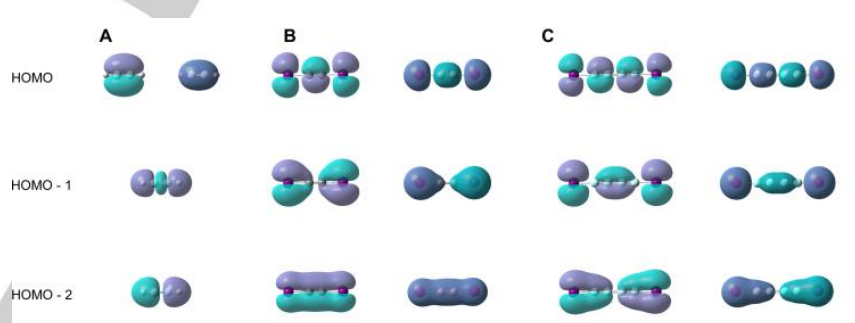

Figure 2. Molecular orbitals of neutral ground state of A) acetylene, B) diiodoacetylene and C) diiododiacetylene, respectively.

The stability of DIA $(\leq 4+)$ was then investigated by theoretical calculations. The DFT calculation was performed in order to obtain the equilibrium structures and electronic energies at fixed electronic configurations for the HOMO, HOMO-1, and HOMO-2 of acetylene and DIA (Figures S3 and S4). The results for optimized bond lengths in acetylene and DIA as a function of the charge and spin multiplicity are shown in Figures $3 a, 3 b$ (Tables S1 to S3). The optimized configuration of the four atoms was linear for both acetylene and DIA. Increasing the number of charges resulted in a monotonic increase in the $\mathrm{C}-\mathrm{H}$ and $\mathrm{C}-\mathrm{C}$ bond lengths. On the other hand, the $\mathrm{C}-\mathrm{I}$ bond in DIA (singlet or doublet) was shortened as the number of charges increased up to four. These results are essentially consistent with the qualitative predictions for $\mathrm{HOMO}$ electron removal to generate the lowest spin states. 


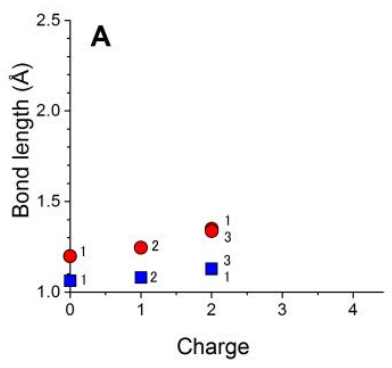

C

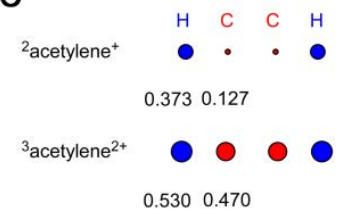

D ${ }^{2} \mathrm{DIA}^{+}$
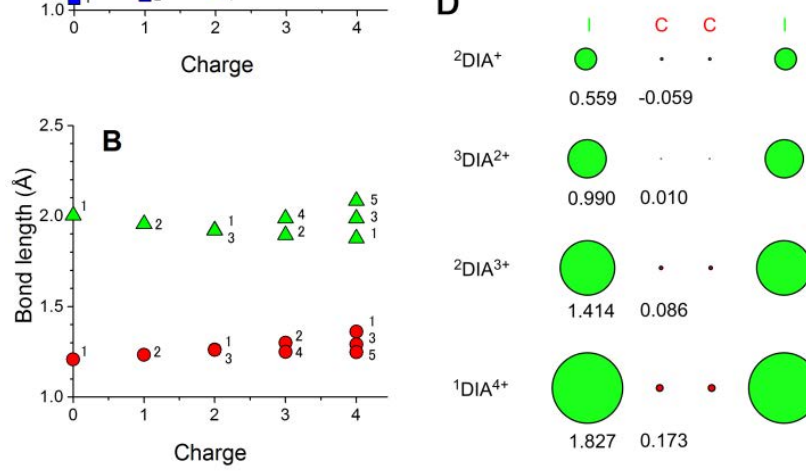

${ }^{3} \mathrm{DIA}^{2+}$ $0.559 \quad-0.059$

\section{${ }^{2} \mathrm{DIA}^{3+}$} $0.990 \quad 0.010$

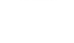

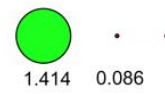

${ }^{1} \mathrm{DIA}^{4+}$

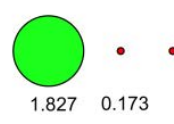

The completely different charge distributions for acetylene and DIA (Figures $3 \mathrm{c}$ and 3d, Tables S4 and S5) are critical for the persistence of the MMCs of DIA. The calculations show that the acetylene dication has nearly equally delocalized positive charges over all their atoms. Hence, we might expect that the repulsive Coulombic interaction between each set of two atoms in acetylene dication is large (2.33-3.18 eV, Table S6). In DIA MMCs, however, the positive charge is mostly (DIA ${ }^{4+}, 91.3-$ 95.2\%; $\mathrm{DIA}^{3+}, \quad 94.2-96.4 \%$; $\mathrm{DIA}^{2+}, \quad 98.7-99.0 \%$, Table S5) localized on the iodine atoms, and thus the repulsion energies between two neighboring atoms even in the DIA tetracation (0.11-2.42 eV, Table S7) are lower than those in the acetylene dication.

It should be mentioned that the contributions of the different MOs having a different symmetry to the single ionization process can be determined with angle-resolved electron and/or ion correlation experiments. ${ }^{[28-29,33]}$ We are not sure that we could apply these methods to DIA possessing the MOs of similar axial symmetry. Future spectroscopic measurements performed after selection and trapping of the desired ion ${ }^{[34]}$ as well as ionization wavelength-dependent dissociation ${ }^{[35]}$ may provide information about the electronic states of the intact MMCs.

Figure 3. Calculated bond lengths of $A$ ) acetylene $(\mathrm{C}-\mathrm{C}, \mathrm{\circ} ; \mathrm{C}-\mathrm{H}, \square)$ and $\mathrm{B})$ diiodoacetylene $(\mathrm{C}-\mathrm{C}, \circ ; \mathrm{C}-\mathrm{I}, \triangle \mathrm{)}$ ) as a function of the charge and spin multiplicity indicated on the right side of the $\circ, \square$, and $\triangle$ symbols. Calculated Mulliken atomic charges for $\mathrm{C}$ ) acetylene and D) diiodoacetylene. The value below the circle indicates the atomic charge. The radius of the circle and distance between the circles indicates for the relative charges and relative distance between the atoms, respectively.

The expectation about the strength of chemical bond should fail when the lower-lying electrons are removed. Removing the acetylene HOMO-1 electrons, for example ${ }^{4}$ acetylene ${ }^{3+}$, should result in fragmentation because the HOMO-1 of acetylene is the $\sigma$ orbital primarily located on the hydrogen and carbon atoms (Figure 2a). Recently, the contribution of electron removal from lower-lying MOs, even in the first tunnel ionization process towards excited monocations in intense laser fields, was experimentally investigated for butane, ${ }^{[27]} \mathrm{HCl},{ }^{[28]}$ and $\mathrm{CO}^{[29]}$ It was also theoretically revealed that bond elongation in intense laser fields enhances the electron ejection probability from the lower-lying MOs forming excited acetylene cation. ${ }^{[30]}$ As the HOMO-1 of DIA is primarily located on the iodine atoms, with a small contribution from corresponding $p$ orbitals on the two carbon atoms, which are separated by a node (Figure $2 b$ ), the slight lengthening of $\mathrm{C}-\mathrm{I}$ bond occurs by the HOMO-1 electron removal as observed in ${ }^{4} \mathrm{DIA}^{3+},{ }^{3} \mathrm{DIA}^{4+}$, and ${ }^{5} \mathrm{DIA}^{4+}$ (Figure $3 \mathrm{~b}$ ). On the other hand, the antibonding characteristic of $\mathrm{C}-\mathrm{I}$ bond, not only in the HOMO but also in the HOMO-1 of DIDA presumably explains the larger yield of DIDA MMCs versus those of DIA (Figure 1c).

Although several states are formed for each charge states, it might be expected that there would be little likelihood of detecting the excited ions by mass spectroscopy owing to their repulsive nature. ${ }^{[27]}$ For example, the lifetime of the acetylene dication $\left(\mathrm{X}^{3} \Sigma_{g}^{-}, \mathrm{a}^{1} \Delta_{g}, \mathrm{~b}^{1} \Sigma_{g}^{+}\right)^{[31]}$ was varied from pico- to microseconds ${ }^{[32]}$ although electrons were ejected from $\mathrm{HOMO} \pi$ orbitals. At present, we may leave the origin of the emitted electrons from DIA unsolved, and consider the lowest energy state, which can be detected by mass spectroscopy.

In summary, we investigated that making use of iodines as the positively charged sites enabled the carbons in DIA tetracation to be maintained in the field formed by the two adjacent iodine ions due to charge-induced attractive dipole interactions. ${ }^{\left[{ }^{[9]}\right.}$ Although the confinement of positive charges in a small room without stabilization by the surroundings is hardly expected in the usual manner, the isolated, bare, and the smallest organic tetracation can hold chemical bondings. The number of charges can be increased by locating the positive charges at specific sites in remote positions, such as poly(trityl cations) $)^{[36]}$ or poly(triarylamine radical cations) ${ }^{[37]}$ in the cases of large polycations, which are synthesized by removing anionic fragments such as hydride ions. Such polycations in the condensed media are stabilized by neutralization with counter anions, solvation with polar molecules and/or maintaining at low temperatures. ${ }^{[38]}$ Multiply protonated large molecules such as proteins and peptides produced via electrospray ionization, ${ }^{[39]}$ did not reduce the strength of chemical bonding, and thus they were stable enough to play important roles in chemical, biological and medical diagnostics. We can propose that DIA tetracation has the potential to be a reactive species due to the persistence of very small molecular framework with a quadruple charge for sufficient duration as well as its large electron affinity $(25.8 \mathrm{eV})$ and potential energy $(69.0 \mathrm{eV})($ Table S2).

\section{Experimental Section}

Gaseous samples were ionized by a focused femtosecond laser pulses from a Ti:Sapphire laser $(0.8 \mu \mathrm{m}, 45 \mathrm{fs}, 100 \mathrm{~Hz}$ or $1 \mathrm{kHz})$. The pressure of the sample in the ionization chamber was kept below $5 \times 10^{-5} \mathrm{~Pa}$ during the experiments to avoid the space-charge effect. A Wiley-McLaren time-of-flight mass spectrometer was used for ion analysis. A density functional theory calculations (Gaussian 09, DFT/B3LYP/6-311G*) $)^{[40]}$ were performed to determine the equilibrium structures and electronic energies of MMCs. 


\section{Acknowledgements}

This research was supported financially in part by JST PRESTO program, JSPS KAKENHI Grant Numbers JP26620014, JP24227002, JP26107002.

Keywords: active species • density functional calculations • laser chemistry $\bullet$ polycations $\bullet$ tunnelling

[1] S. L. Chin, C. Rolland, P. B. Corkum, P. Kelly, Phys. Rev. Lett. 1988 , $61,153-156$.

[2] K. W. D. Ledingham, R. P. Singhal, D. J. Smith, T. McCanny, P Graham, H.S. Kilic, W. X. Peng, S. L. Wang, A. J. Langley, P. F. Taday, C. Kosmidis, J. Phys. Chem. A 1998, 102, 3002-3005.

[3] L. J. Frasinski, K. Codling, P. A. Hatherly, Science 1989, 246, 10291031.

[4] M. Pitzer, M. Kunitski, A. S. Johnson, T. Jahnke, H. Sann, F. Sturm, L. Ph. H. Schmidt, H. Schmidt-Böcking, R. Dörner, J. Stohner, J. Kiedrowski, M. Reggelin, S. Marquardt, A. Schießer, R. Berger, M. S Schöffler, Science, 2013, 341, 1096-1100

[5] J. D. Fletcher, M. A. Parkes, S. D. Price, Chem. Eur. J. 2013, 19, 10965-10970.

[6] D. Mathur, Phys. Rep. 1993, 225, 193-272.

[7] K. Vékey, Mass Spectrom. Rev. 1995, 14, 195-225.

[8] D. Schröder, Angew. Chem. Int. Ed. 2004, 43, 1329-1331.

[9] a) D. Schröder, H. Schwarz, J. Phys. Chem. A 1999, 103, 7385-7394 b) D. Schröder, J. N. Harvey, H. Schwarz, J. Phys. Chem. A 1998, 102 3639-3642.

[10] A. S. Newton, J. Chem. Phys. 1964, 40, 607-608.

[11] a) V. Brites, K. Franzreb, J. N. Harvey, S. G. Sayres, M. W. Ross, D. E. Blumling, A. W. Castleman, M. Hochlaf, Phys. Chem. Chem. Phys. 2011, 13, 15233-15243; b) H. Hammami, O. Yazidi, M. Ben El Had Rhouma, M. M. Al Mogren, M. Hochlaf, J. Chem. Phys. 2014, 141 014302

[12] G. W. Burdick, J. R. Appling, T. F. Moran, J. Phys. B 1986, 19, 629-641.

[13] M. M. Bursey, P. F. Rogerson, J. M. Bursey, Org. Mass Spectrom 1970, 4, 615-617.

[14] T. Yatsuhashi, N. Nakashima, J. Phys. Chem. A 2010, 114, 7445-7452.

[15] A. Lawicki, A. I. S. Holm, P. Rousseau, M. Capron, R. Maisonny, S. Maclot, F. Seitz, H. A. B. Johansson, S. Rosen, H. T. Schmidt, H. Zettergren, B. Manil, L. Adoui, H. Cederquist, B. A. Huber, Phys. Rev. A 2011, 83, 022704.

[16] V. R. Bhardwaj, P. B. Corkum, D. M. Rayner, Phys. Rev. Lett. 2003, 91 , 203004

[17] R. G. Kingston, M. Guilhaus, A. G. Brenton, J. H. Beynon, Org. Mass Spectrom. 1985, 20, 406-412.

[18] a) T. Yatsuhashi, N. Mitsubayashi, M. Itsukashi, M. Kozaki, K. Okada N. Nakashima, ChemPhysChem 2011, 12, 122-126; b) N. Mitsubayashi, T. Yatsuhashi, H. Tanaka, S. Furukawa, M. Kozaki, K. Okada, N. Nakashima, Int. J. Mass Spectrom. 2016, 403, 43-52.
[19] S. Feil, K. Gluch, A. Bacher, S. Matt-Leubner, D. K. Bohme, P. Scheier, T. D. Mark, J. Chem. Phys. 2006, 124, 214307.

[20] E. Kloster-Jensen, C. Pascual, J. Vogt, Helv. Chim. Acta. 1970, 53, 2109-2118

[21] C. Cornaggia, M. Schmidt, D. Normand, Phys. Rev. A 1995, 51, 1431 1437.

[22] A. Hishikawa, A. Matsuda, M. Fushitani, E. J. Takahashi, Phys. Rev Lett. 2007, 99, 258302

[23] D. Mathur, A. K. Dharmadhikari, F. A. Rajgara, J. A. Dharmadhikari, Phys. Rev. A 2008, 78, 013405

[24] A. S. Alnaser, S. Voss, X. M. Tong, C. M. Maharjan, P. Ranitovic, B. Ulrich, T. Osipov, B. Shan, Z. Chang, C. L. Cocke, Phys. Rev. Lett. 2004, 93, 113003

[25] T. Kinugawa, P. Lablanquie, F. Penent, J. Palaudoux, J. H. D. Eland, J. Electron. Spectrosc. Relat. Phenom. 2004, 141, 143-148.

[26] D. Klapstein, J. P. Maier, W. Zambach, Chem. Phys. 1983, 77, 463-475.

[27] A. E. Boguslavskiy, J. Mikosch, A. Gijsbertsen, M. Spanner, S. Patchkovskii, N. Gador, M. J. J. Vrakking, A. Stolow, Science 2012, 335, 1336-1340.

[28] H. Akagi, T. Otobe, A. Staudte, A. Shiner, F. Turner, R. Dorner, D. M. Villeneuve, P. B. Corkum, Science 2009, 325, 1364-1367.

[29] J. Wu, L. Ph. H. Schmidt, M. Kunitski, M. Meckel, S. Voss, H. Sann, H. Kim, T. Jahnke, A. Czasch, R. Dörner, Phys. Rev. Lett. 2012, 108 183001.

[30] E. Lötstedt, T. Kato, K. Yamanouchi, Phys. Rev. A 2012, 85, 041402.

[31] O. Furuhashi T. Kinugawa, S. Masuda, C. Yamada, S. Ohtani, Chem .Phys. Lett. 2001, 342, 625-630.

[32] M. Alagia, C. Callegari, P. Candori, S. Falcinelli, F. Pirani, R. Richter, S. Stranges, F. Vecchiocattivi, J. Chem. Phys. 2012, 136, 204302.

[33] H. Niikura, H. J. Wörner, D. M. Villeneuve, P. B. Corkum, Phys. Rev. Lett. 2011, 107, 093004

[34] R. D. Smith, X. Cheng, J. E. Bruce, S. A. Hofstadler, G. A. Anderson, Nature 1994, 369, 137-139.

[35] T. Bohinski, K. M. Tibbetts, K. Munkerup, M. Tarazkar, D. A. Romanov, S. Matsika, R. J. Levis, J. Chem. Phys. 2014, 442, 81-85.

[36] J. C. Barnes, A. C. Fahrenbach, D. Cao, S. M. Dyar, M. Frasconi, M. A Giesener, D. Benitez, E. Tkatchouk, O. Chernyashevskyy, W. H. Shin H. Li, S. Sampath, C. L. Stern, A. A. Sarjeant, K. J. Hartlieb, Z. C. Liu, R. Carmieli, Y. Y. Botros, J. W. Choi, A. M. Z. Slawin, J. B. Ketterson, M. R. Wasielewski, W. A. Goddard, J. F. Stoddart, Science 2013, 339, 429-433.

[37] N. J. Head, G. K. S. Prakash, A. Bashirhashemi, G. A. Olah, J. Am Chem. Soc. 1995, 117, 12005-12006.

[38] G. A. Olah, G. K. Surya Prakash, J. Sommer, A. Molnar in Superacid Chemistry, 2nd Ed., Wiley-VCH, New York, 2009, chap. 3.

[39] J. B. Fenn, M. Mann, C. K. Meng, S. F. Wong, C. M. Whitehouse Science 1989, 246, 64-71.

[40] M. J. Frisch et al., Gaussian 09, Revision D.01, Gaussian, Inc. Wallingford CT, 2009 


\section{Entry for the Table of Contents}

Layout 2:

\section{COMMUNICATION}

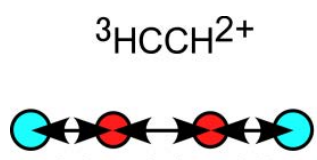

$\begin{array}{lll}3.2 & 2.4 & 3.2\end{array}$

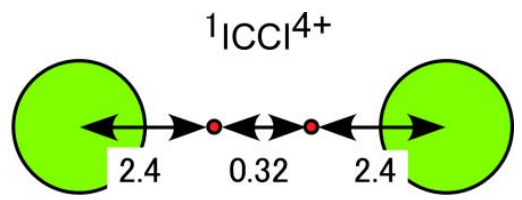

Coulomb repulsion energy in eV units

How to avoid dissociation: Contrary to acetylene dication delocalizing its positive charges over the molecule (left), diiodoacetylene tetracation (right) survives after the removal of four electrons by localizing its positive charges on the terminal iodine atoms, ensuring minimum Coulomb repulsion between adjacent atoms as well as maximum charge-induced attractive dipole interactions between iodine and carbon (see picture).
Tomoyuki Yatsuhashi, ${ }^{\star}$ Kazuo Toyota, Naoya Mitsubayashi, Masatoshi Kozaki, Keiji Okada, and Nobuaki Nakashima

Page No. - Page No.

Intact Four-atom Organic Tetracation Stabilized by Charge Localization in the Gas Phase 